\title{
Gelişmekte Olan Piyasalarda Finansal Bağlantılılık
}

\author{
DOI: 10.26466/opus. 778653
}

\author{
*

\section{Eray Gemici *} \\ * Dr. Öğretim Üyesi, Gaziantep Üniversitesi, İslahiye İktisadi ve İdari Bilimler Fakültesi, \\ Gaziantep/Türkiye \\ E-Posta: gemici@gantep.edu.tr \\ ORCID: 0000-0001-5449-0568

\section{Öz}

Bu çalışma, gelişmekte olan E7 ülke borsaları (Brezilya, Rusya, Hindistan, Çin, Endonezya, Meksika ve

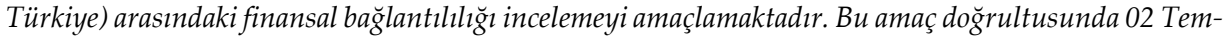
muz 1997-24 Haziran 2020 dönemi için E7 ülke borsaları arasındaki finansal bağlantılılık Diebold ve Yılmaz $(2009,2012)$ yöntemi ile incelenmiştir. Çalışmada elde edilen bulgular, E7 ülke borsaları arasındaki toplam volatilite yayılım endeksinin düşük seviyede olduğunu ortaya koymuştur. Özellikle diğer ülkelere doğru en yüksek finansal risk geçişinin ve risk alışının sırasıyla Meksika ve Brezilya borsalarından kaynaklandığg görülmüştür. Diğer yandan Çin borsası, diğgr altı ülke piyasalarına göre risk yayma ve risk alma noktasında düşük seviyede kalmıştır. Ayrıca toplam volatilite endeksi 200 günlük kayan pencereler yaklaşımına göre incelenmiş ve E7 ülke borsaları arasındaki finansal risk geçişinin en yüksek olduğu dönem COVID-19 pandemi dönemi olarak tespit edilmiştir. Çalışmadan elde edilen bulgular dikkate alındı̆̆ı̆da çalışmanın portföy çeşitlendirmesinde ve piyasa volatilitesinin tahmin edilmesi için portföy yöneticileri ve piyasa düzenleyiciler için önem arz ettiği düşünülmektedir

Anahtar Kelimeler: Finansal bağlantılılık, toplam yayılma endeksi, gelişmekte olan piyasalar. 


\title{
Financial Connectedness in Emerging Markets
}

*

\begin{abstract}
This study aims to examine the financial connectedness between emerging E7 (Brazil, Russia, India, China, Indonesia, Mexico and, Turkey) stock markets. For this purpose, the connectedness between E7 stock markets was examined using the Diebold and Yilmaz $(2009,2012)$ method for the period of 02 July 1997 - 24 June 2020. The findings of the study revealed that the total volatility spillover index among E7 country stock markets was low level. It was seen that the highest financial risk transition and risk receiving to other countries originated from the Mexican and Brazilian stock markets, respectively. On the other hand, the Chinese stock market remained at a low level in terms of risk transmission and risk receiving compared to the markets of the other six countries. In addition, the total volatility index was analyzed according to the 200-day rolling windows approach and the highest financial risk transition between E7 country stock markets was determined as the COVID-19 pandemic period. However, according to the 200-day rolling windows approach, the period in which the financial risk transition between E7 country stock markets is the highest indicates the COVID-19 pandemic period. Considering the findings obtained from the study, it is thought that the study is important for portfolio managers and market regulators in portfolio diversification and for estimating market volatility.
\end{abstract}

Keywords: Financial connectedness, total spillover index, emerging markets. 


\section{Giriş}

Finansal küreselleşme süreci ile ekonomik sistemler, ticaret ilişkileri, yatırım ağları ve tedarik zincirleri karşılıklı bağımlılık noktasında daha fazla entegre hale gelmiştir (Gong, Liu, Xiong ve Zhang, 2019, s.290). Ancak daha fazla uluslararası finansal entegrasyon, sınır ötesi sermaye hareketliliğini ve oynaklık yayılmalarını kolaylaştıran bir faktör olarak karşımıza çıkmaktadır (Vo ve Tran, 2020, s.1). Dolayısıyla, çeşitli finansal piyasalar arasındaki korelasyonlar ve etkileşimler hakkında bilgi sahibi olmak yatırımcılar, finansal kurumlar ve hükümetler için oldukça önemli bir konu haline gelmiştir (Zhou, Zhang ve Zhang, 2012, s.247). Çünkü uluslararası piyasalardaki bağlantılıl1ğın güçlü bir özellik göstermesi, iç piyasaları dışarıdan gelebilecek herhangi bir şoka karşı dirençli hale getirirken, zayıf bir bağlantılılık uluslararası çeşitlendirmeden kaynaklı potansiyel kazançların elde edilmesine olanak sağlamaktadır (Singh, Kumar ve Pandey, 2010, s.55). Bu bakımdan yatırımclar ve portföy yöneticilerinin daha fazla çeşitlendirme yapabilmeleri için çeşitli piyasalar veya varlık sınıfları arasındaki yayılım, piyasalar arasındaki ortak hareketler ve piyasaların karşılıklı bağımlılığı hakkında bilgi sahibi olabilmeleri gerekmektedir (Yoon, Al Mamun, Uddin ve Kang, 2019, s.801). Ayrıca çeşitli coğrafi bölgelerdeki borsalar arasındaki getiri ve volatilite (oynaklık) yayılımlarının incelenmesi de önemli bir faktör olarak görülmektedir (Yarovaya, Brzeszczyński ve Lau, 2016, s.96).

Bir ekonomiden kaynaklanan olumsuz şokların diğer ülkelerin finansal piyasalarına yayılması olarak adlandırılan volatilite yayılımı (Gamba-Santamaria, Gomez-Gonzalez, Hurtado-Guarin ve Melo-Velandia, 2017, s.207), finans literatüründe özellikle 2008 küresel ekonomik krizi ile birlikte oldukça sık çalışılan konulardan biri haline gelmiştir. Yarovaya vd. (2016) konunun bu kadar ilgi görmesinin sebebini, pratik öneminin yanı sıra oynaklı̆̆ın zamanla değişen doğasına bağlamaktadır.

Kriz dönemlerinde finansal piyasalardaki oynaklık sert bir şekilde artarak piyasalar arasında bağlantılılığa yol açmaktadır (Diebold ve Yılmaz, 2009, 2012). Özellikle küresel piyasalardaki bağlantılılık düzeyi, ABD'nin eşik-altı ipotekli konut piyasasında ortaya çıan küresel ekonomik krizle birlikte belirgin hale gelmiş ve dünyada neredeyse tüm ekonomileri ve finansal sistemi etkisi altına alarak (Çamlıca, Güneş ve Özen, 2017, s.3) yatırımcılar için 
önemli kayıplara yol açmış, birçok finansal kurumun iflasına ve yatırımcı güveninde düşüşe ve bunun sonucunda küresel ekonomi üzerinde olumsuz etkilere neden olmuştur (Bala ve Takimoto, 2017, s.25).

Özellikle, 90'ların sonundaki krizlerden sonra, gelişmekte olan ülkelerin ekonomik ve finansal istikrar bakımından ilerleme kaydetmesinin gelişmiş piyasalardan gelişmekte olan piyasalara yönelik oynaklık yayılım modelinin değişmesine neden olduğu iddia edilmektedir (Cardona, Gutiérrez ve Agudelo, 2017, s.115). Bu durum, gelişmiş piyasalardan kaynaklanan şoklardan ziyade, gelişmekte olan piyasalardaki şokların yayılımına odaklanılmasını sağlamıştır (Beirne, Caporale, Schulze-Ghattas ve Spagnolo, 2013, s.1061). Nitekim, Tayland'da başlayan ve hızlı bir şekilde Malezya, Filipinler, Endonezya, Kore, Tayvan ve Hong Kong gibi Asya ekonomilerini etkileyen 1997 mali ve döviz krizi hem finansal piyasalarda hem de reel sektör üzerinde ciddi etkilere yol açmış (Chancharoenchai ve Dibooglu, 2006, s. 4) ve aynı zamanda konuya ilişkin literatürün, kullanılan ekonometrik model ve yöntemlerin gelişmesini de beraberinde getirmiştir.

Literatürde sıklıkla kullanılan ekonometrik yöntemlerden birisi de Diebold ve Yılmaz $(2009 ; 2012)$ tarafindan önerilen ve volatilite yayılımının yönlü ölçütünün tahmininde kullanılan yöntemdir. Diebold ve Yılmaz (2009) söz konusu yöntemin, getiri veya getiri volatilitelerini, ülke içi ve ülkeler arasındaki varlıkların, varlık portföylerinin ve varlık piyasalarının vs. arasındaki yayılma eğilimlerinin, döngülerinin, patlamalarının vb. ölçülmesinde kullanılabileceğini belirtmiş (Diebold ve Yılmaz, 2009, s.2) ve 1 Ocak 2004'ten son gözlem aşamasına kadar 45 ülkenin günlük borsa endeks getiri volatilitelerine uyguladıkları Diebold - Yılmaz Volatilite Bağlantılılık Endeksini geliştirmişlerdir.

Şekil 1, 2 Ağustos 2004 - 15 Mayıs 2020 dönemi için 45 ülkenin tamamı için günlük bazda hesaplanmış olan Diebold - Yılmaz volatilite bağlantilılık endeksini göstermektedir. 


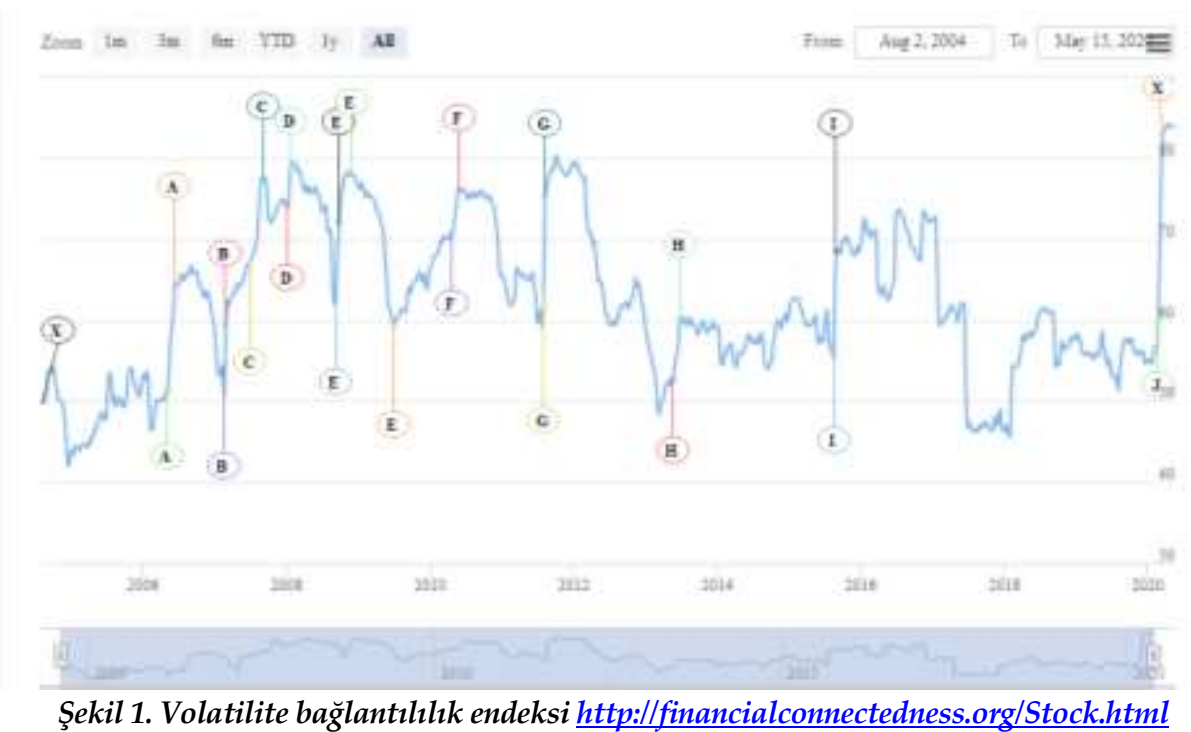

Şekil 1'de görüldüğü üzere incelenen periyotta volatilite endeksi, piyasadaki haber ve gelişmelere göre artış ve azalışlar sergilemektedir. Örneğin, şekilin dikey ekseninde ilk A ile ifade edilen olay FED'in faiz artırım kararı ve faiz arbitrajında gevşeme öncesi dönem olan 9 Mayıs 2006 tarihini göstermektedir. Bu tarihte yaklaşık 51 seviyesinde olan endeks, faiz artırma kararı ve faiz arbitrajında gevşeme sonrası dönem olan 15 Haziran 2006 tarihinde (ikinci A) 64 seviyesine kadar yükselmiştir. Benzer şekilde ilk E ile ifade edilen olay dünyanın en büyük yatırım bankalarından biri olan Lehman Brothers'in iflas öncesi tarihi olan 10 Eylül 2008 tarihini göstermektedir. Bu tarihte 61 civarında olan endeks, iflasın açıklandığı tarihten sonra 25 Eylül 2008 tarihinde (ikinci E) 70 seviyesine kadar yükselmiş ve nihai olarak 27 Kasım 2008 tarihinde (üçüncü E) 78 seviyesine gelerek küresel krizin sinyallerini vermiştir.

Şekilde yer alan ve J ve X olarak ifade edilen kısım son dönemde pandemi haline gelen COVID-19'a işaret etmektedir. J harfi ile ifade edilen tarih piyasaların COVID-19 salgınından endişelenmediği dönemi gösteren 21 Şubat 2020 tarihinde endeks 56 seviyesinde iken, 20 Mart 2020 tarihinde 83 sevisine doğru tırmanarak tarihinin en yüksek seviyesine gelmiştir. 
Diebold-Yılmaz Volatilite Bağlantılılık Endeksi sadece küresel hisse senedi piyasalarında değil aynı zamanda döviz piyasaları, devlet tahvili piyasaları ve CDS piyasaları için de hesaplanmıştır. Ancak bu çalışma kapsamında bu endekslere değinilmemiş olup, endekslere ilişkin gerekli veri seti ve metodolojiye http://financialconnectedness.org/ web adresinden ulaşılabilmektedir.

Finansal piyasalardaki oynaklıklar yerel piyasalardan meydana gelen şoklardan kaynaklanabildiği gibi uluslararası çapta yaşanan mali olaylardan da kaynaklanabilmektedir. Ancak günümüz koşullarında finansal liberalizasyonun etkisiyle yerel çapta yaşanan krizler sadece o piyasada etkisini göstermemektedir. Çünkü uluslararası piyasa katılımcıları bir ülkede yaşanan şoku o ülke vatandaşı gibi anında öğrenebilmekte ve buna göre piyasalarda pozisyon alabilmektedir. Dolayısıyla, bilginin hızla yayıldığı günümüzde finansal piyasalarda yaşanan olumlu veya olumsuz olaylar çeşitli ülke piyasalarına sirayet edebilmektedir. Bu sebeple, gerek finansal piyasaların kontrol altında tutmaya çalışan devletler ve regülatörler gerekse de portföy yöneticileri ve yatırımcılar için piyasalar arası bağlantılılık ve volatilite yayılımı konusu oldukça önemli bir hale gelmiş ve finans literatüründe araştırmacılar tarafından çeşitli yöntemlerle farklı varlık piyasalarında hala incelenmeye devam etmektedir.

Volatilite yayılımı ile ilgili yapılan araştırmalar incelendiğinde çeşitli ekonometrik yöntemlerle ve çeşitli varlık piyasalarında yayılım etkisinin test edildiği görülmektedir. GARCH modelleri (Do, Powell, Yong ve Singh, 2019; Mishra, 2019; Ng, 2000; Toraman, İğde, Buğan ve Kılıç, 2016; Umer, Coşkun ve Kiracl, 2018; M. Wu ve Zhu, 2019), rejim değişim modeli (Baele, 2005), dinamik ARDL testi (Faizulayev ve Wada, 2019), dalgacık analizi yaklaşımı (Kumar ve Kamaiah, 2017), kantil regresyon analizi (Ben Rejeb, 2016) gibi yöntemler literatürde kullanılan yöntemlerden bazılarıdır. Spesifik olarak hisse senedi piyasaları volatilite yayılım etkisinin en fazla araştırıldığı piyasalar olmakla birlikte bu piyasalar haricinde Avrupa tahvil piyasaları (Christiansen, 2007) , döviz piyasaları (Lee, 2009; Qayyum ve Kemal, 2006), altın ve enerji futures ve spot piyasaları (Priya, 2008), gayrimenkul piyasaları (Liow ve Huang, 2018), gida fiyatları (Alom, Ward ve Hu, 2011), misir ve ham petrol piyasaları (F. Wu, Guan ve Myers, 2011), petrol ve tarım emtia piyasaları (Du, Yu ve Hayes, 2011; Nazlıoğlu, Erdem ve Soytaş, 2013), enerji piyasaları (Ka- 
rali ve Ramirez, 2014), Bitcoin ve menkul kıymet piyasaları (Kamışlı ve Temizel, 2019; Qarni, Gulzar, Fatima, Khan ve Shafi, 2019) örneklem olarak çalışmalarda kullanılmıştır.

Literatürde hisse senedi piyasalarında volatilite yayılım etkisini inceleyen çok sayıda araştırma vardır. Singh vd. (2010) Kuzey Amerika, Avrupa ve Asya borsaları arasındaki getiri ve oynaklık yayılımını 1 Ocak 2000 - 22 Şubat 2008 dönemi için inceledikleri çalışma sonucunda getiri ve oynaklık yayılımınin ABD piyasasından Japonya, Kore, Singapur, Tayvan, Hong Kong ve Avrupa piyasalarına doğru gerçekleştiğini tespit etmişlerdir. Joshi (2011) Asya Borsaları (Hindistan, Hong Kong, Japonya, Çin, Endonezya ve Kore) arasındaki getiri ve oynaklık yayılımını 2 Şubat 2007 -29 Şubat 2010 periyodu için araştırdığı çalışmada Hindistan ile Hong Kong, Japonya, Endonezya ve Kore arasında çift yönlü oynaklık yayılımı, benzer şekilde Hong Kong ile Japonya ve Endonezya ile Kore arasında da yine çift yönlü oynaklık yayılımı olduğu sonucuna ulaşmıştır. Aloui (2011) Latin Amerika Ülkeleri (Arjantin, Brezilya, Şili, Meksika) için risk yayılımını Ocak 1995-Eylül 2009 dönemini kapsayan verilerle incelemiştir. Latin Amerika piyasaları arasındaki koşullu korelasyonların zaman içerisinde değiştiğini ve gelişmekte olan komşu ülkelerin bölgedeki risk yayılımına katkıda bulunduğunu tespit etmiştir. Korkmaz vd. (2012) CIVETS ülke borsaları (Kolombiya, Endonezya, Vietnam, Mısır, Türkiye ve Güney Afrika) arasındaki volatilite yayılımın 24 Temmuz 2002-29 Aralık 2010 dönemi için inceledikleri çalışmada CIVETS piyasaları arasında eş zamanlı getiri ve oynaklık yayılımlarının düşük olduğunu ve bu yayılımların özellikle piyasaların birbirlerine olan bağımlılıklarından kaynaklandığını ortaya koymuşlardır. Li ve Giles (2015) Gelişmiş ülke borsaları (ABD ve Japonya) ve gelişmekte olan Asya borsaları (Çin, Hindistan, Endonezya, Malezya, Filipinler ve Tayland) arasındaki volatilite yayılımın 1 Ocak 1993-31 Aralık 2012 dönemi için inceledikleri çalışmada, ABD piyasasından Japonya ve gelişmekte olan Asya piyasalarına yönelik tek yönlü volatilite yayılımı tespit etmişlerdir. Alotaibi ve Mishra (2015) Suudi Arabistan, ABD ve Körfez ülke borsaları (Bahreyn, Umman, Kuveyt, Katar, Birleşik Arap Emirlikleri) arasındaki getiri ve oynaklık yayılımlarını Haziran 2005-Mayıs 2013 periyodu için araştırmışlardır. Ortalamada getiri yayılımı açısından Suudi Arabistan ve ABD'den Körfez ülke piyasalarına yönelik anlamlı bir etki tespit etmişlerdir. Ayrıca ticaret, GSYİH ve kurumsal kalite değişkenlerinin Suudi 
Arabistan'dan Körfez ülke piyasalarına olan bölgesel volatilite yayılımlarında pozitif bir etkiye sahip değişkenler olduğu sonucuna ulaşmışlardır. Kırkulak Uludağ ve Khursid (2019) Çin borsasından E7 ve G7 borsalarına olan volatilite yayılımını 1 Eylül 1995-3 Mart 2015 dönemi için incelemişlerdir. Çalışma sonucunda Çin hisse senedi piyasasından E7 ve G7 hisse senedi piyasalarına önemli volatilite yayılımı olduğunu, en yüksek volatilite yayılımının E7 ülke grubu içeresinde Çin ile Hindistan arasında; G7 ülke grubu içerisinde ise Çin ile Japonya arasında olduğunu tespit etmişlerdir.

$\mathrm{Bu}$ araştırmanin metodolojisini oluşturan Diebold ve Yılmaz $(2009,2012)$ yönteminin kullanıldığı araştırmalar ise aşağıda detaylı bir şekilde özetlenmiştir. Bu doğrultuda ilk olarak finansal piyasaları inceleyen araştırmalar aşağıda özetlenmiştir.

Yılmaz (2010) Doğu Asya ülkeleri (Hong Kong, Endonezya, Japonya, Güney Kore, Malezya, Filipinler, Singapur, Tayvan, Tayland ve Avustralya) arasındaki getiri ve volatilite bağlantılılığını 1 Ocak 1992-30 Nisan 2009 haftalık verilerle incelediği çalışma sonucunda kriz dönemleri ve kriz olmayan dönemlerde getiri ve volatilite yayılımının zaman içinde farklılaştığını ortaya koymuştur. Özellikle piyasalar arasındaki getiri ve volatilite yayılım endeksinin 2008 küresel kriz döneminde zirve yaptığını tespit etmiştir. Diebold ve Yılmaz (2012) ABD hisse senedi, tahvil, döviz ve emtia piyasalarında günlük volatilite yayılımları Ocak 1999-Ocak 2010 dönemi için geliştirmiş oldukları tahmin hatası varyans ayrışımlarının değişken sıralamasına göre değişmediği genelleştirilmiş bir VAR çerçevesi ile incelemişlerdir. Çalışma sonucunda, incelenen dört piyasanın tamamında önemli oynaklık dalgalanmalarının olduğunu, özellikle 2008 Eylül ayında Lehman Brothers'ın iflasını açılamasından sonra piyasalar arasında oynaklık dalgalanmalarının önemli ölçüde arttığını tespit etmişlerdir. Barunik vd. (2016) ABD hisse senedi piyasasinda 2004'ten 2011'e kadar yedi sektörden en likit yirmi bir hisse senedi arasındaki bağlantılılığı incelediği çalışmalarında, hisse senetleri arasında asimetrik volatilite yayılımı olduğunu ortaya koymuşlardır. Chow (2017) ABD, İngiltere ve 10 Asya ülkesi (Çin, Hong Kong, Endonezya, Japonya, Kore, Malezya, Filipinler, Singapur, Tayvan) arasındaki volatilite yayılımını Eylül 1999-Mayıs 2016 dönemi için kriz öncesi dönem, kriz dönemi ve kriz sonrası dönem olmak üzere alt dönemler halinde incelemiştir. Çalışma sonucunda tüm Asya borsalarının, kriz öncesi döneme kıyasla, kriz sonrası dönemde 
ekonomik ortamdaki belirsizliğin etkisiyle dış borsalardan yayılan volatiliteye maruz kaldıklarını tespit etmiştir. Çamlıca vd. (2017) Türkiye'de finansal bağlantılılık yapısını 2002-2017 dönemi için inceledikleri çalışmada hisse senedi piyasası, para piyasası ve döviz piyasasının risk transferinde öncü olduğunu, tahvil ve bankacılık piyasalarının ise risk aktarım mekanizmasında alıc bir rol üstlendiğini tespit etmişlerdir. Mensi vd. (2018) ABD S\&P 500 endeksi, Avrupa stoxx600 endeksi, Asya Pasifik bölgeleri temsilen P1DOW endeksi ve GIPSI (Yunanistan, İrlanda, Portekiz, İspanya ve İtalya) borsaları arasındaki risk bağlantılılı̆̆ını incelediği çalışma sonucunda Avrupa ve Asya / Pasifik bölgesel piyasaları ve İspanya ve Yunanistan piyasalarının diğer piyasalardan gelen şoklara karşı duyarlı olduğu, İrlanda, Portekiz, İtalya ve $\mathrm{ABD}$ piyasalarının şok aktarım mekanizmasında net verici bir rol üstlendiği sonucuna ulaşmışlardır. Polat (2018) G-7, Türkiye ve Norveç ülkelerinin hisse senedi piyasa endeksleri arasındaki finansal bağlantılılığ 1/1/1998-27/2/2018 dönemi için incelediği çalışma sonucunda kriz gibi belirsizlik ve çalkantı dönemlerinde finansal piyasa endeksleri arasında bağlantılılığın arttığını tespit etmiştir. Özellikle ABD'de meydana gelen küresel krizin etkisiyle birlikte ABD'nin diğer piyasalara net finansal risk yaydığını yine benzer şekilde İngiltere'de yapılan Brexit referandumu sürecinde de İngiltere'den diğer ülkelere yüksek finansal risk geçişi olduğunu tespit etmiştir. Jeong ve Park (2018) Kore finansal piyasasındaki finansal kurumlar arasındaki bağlantılılığı Ocak 1990-Temmuz 2015 dönemi için inceledikleri çalışma sonucunda özelikle kriz dönemlerinde (1997 Asya Krizi ve 2007/2008 Küresel kriz) bağlantılılığın arttığını ve finansal kurumlar arasındaki bağlantı yoğunluğundaki artışı bu kurumların hisse senedi fiyatlarındaki oynaklığı da beraberinde getirdiğini ortaya koymuşlardır.

Finansal piyasaların yanı sıra hem diğer varlık piyasalarının hem borsalarla farklı piyasa ve ekonomik faktörlerin ele alındığı hem de kripto para piyasası gibi daha yeni piyasalarda volatilite bağlantılılı̆̆ın incelendiği çalışmalar da aşağıdaki şekilde özetlenmiştir.

Balcilar vd. (2019) S\&P 500, ham petrol ve altın arasındaki bağlantılılığ Ocak 1986 ile Ağustos 2018 dönemini inceledikleri çalışma sonucunda altın, petrol ve hisse senetleri arasında volatilite yayılım etkisi tespit etmişlerdir. Abbas vd. (2019) G7 ülke borsaları ile makro ekonomik faktörler (sanayi üretim endeksi, para arzı, faiz oranları, enflasyon, petrol fiyatları ve döviz kurları) arasındaki bağlantılılığı Temmuz 1985 ile Haziran 2015 arasında aylık 
veriler kullanarak genelleştirilmiş VAR metodolojisi ile incelemişlerdir. Analizler sonucunda G-7 borsalarının getirileri ve oynaklıkları ile bahsi geçen makro ekonomik faktörler arasında güçlü bir etkileşim olduğunu, yönlü yayılma ilişkisinin ise İngiltere için tek yönlü, diğer G-7 ülkeleri için ise çift yönlü olduğunu tespit etmişlerdir. Reboredo ve Ugolini (2020) yeşil tahvil ve hazine bonosu, şirket tahvili, yüksek getirili şirket tahvilleri, hisse senedi, döviz ve enerji emtia piyasaları arasındaki fiyat bağlantılılığını yapısal vektör otoregresif (VAR) modelini kullanarak incelemişlerdir. Çalışma sonucunda Ekim 2014-Haziran 2019 dönemi için yeşil tahvil piyasasının hazine bonosu ve döviz piyasalarıyla yakından bağlantılı olduğunu ancak bağlantılılı̆ın hisse senedi, enerji ve yüksek getirili şirket tahvilleri ile zayıf olduğu sonucuna ulaşmışlardır. Zeng vd. (2020) Bitcoin ve konvansiyonel varlıklar olarak hisse senetleri, petrol ve altın arasındaki bağlantılılığ inceledikleri çalışma sonucunda Bitcoin ve geleneksel varlıklar arasındaki bağlantının zayıf olduğunu tespit etmişlerdir.

Bu çalışmanın amacı, Diebold ve Yılmaz $(2009,2012)$ yöntemi kullanılarak gelişmekte olan E7 (Brezilya, Rusya, Hindistan, Çin, Endonezya, Meksika ve Türkiye) piyasaları arasındaki finansal bağlantılılığı incelemektir. Literatürde Diebold ve Yılmaz $(2009,2012)$ metodolojisini takip eden sinırlı sayıda çalışma söz konusudur. Çalışmanın hem bu yönüyle hem de bildiğimiz kadarıyla literatürde yer alan araştırmalardan farklı bir ülke grubunu ele alması nedeniyle mevcut literatüre katkı sağlayacağı düşünülmektedir.

Çalışma genel olarak dört bölümden oluşmaktadır. Devam eden ikinci bölümde veri seti ve yöntem hakkında bilgi verilmiş, üçüncü bölümde çalışmadan elde edilen bulgular özetlenmiş ve çalışma sonuç ve önerilerin yer aldığı dördüncü bölüm ile sonlandırılmıştır.

\section{Veri Seti ve Yöntem}

Çalışmada gelişmekte olan yedi ülke borsasının (E7) (Brezilya, Rusya, Hindistan, Çin, Endonezya, Meksika ve Türkiye) 02 Temmuz 1997 - 24 Haziran 2020 dönemi için günlük getirilerinin volatilitesi veri seti olarak belirlenmiştir. Veriler, toplam 5.996 günlük gözlemden oluşmaktadır. Çalışmanın veri seti www.investing.com web sitesinden elde edilmiştir. Günlük varyansın hesaplanmasında Diebold ve Yılmaz (2012)'yi takiben eşitlik 1'de yer alan Parkinson (1980) yöntemi kullanılmıştır. 


$$
\tilde{\sigma}_{i t}^{2}=0.361\left[\ln \left(P_{i t}^{\max }\right)-\ln \left(P_{i t}^{\min }\right)\right]^{2}
$$

Eşitlik 1'de yer alan $P_{i t}^{\max }$, t gününde i piyasasında gerçekleşen en yüksek fiyattır ve $P_{i t}^{\text {min }} t$ gününde i piyasasında gerçekleşen en düşük fiyatı göstermektedir. $\tilde{\sigma}_{\mathrm{it}}^{2}$, günlük varyansı göstermektedir. Yıllık olarak hesaplanan günlük yüzde standart sapma (volatilite) $\tilde{\sigma}_{\text {it }}=100 \sqrt{365 \tilde{\sigma}_{\text {it }}^{2}}$ olarak elde edilmiştir.

Diebold ve Yılmaz (2009), piyasalar arasındaki volatilite yayılımının derecesini ölçmek için, değişkenlerin sırasına bağlı olarak tahmin hata varyansı ayrışımlarına dayanan DY (2009) endeksini geliştirmiştir. Diebold ve Yılmaz (2012), çalışmasında DY (2009) metodolojisini daha genişleterek, tahmin hatası varyans ayrışımlarının değişken sıralamasına göre değişmediği genelleştirilmiş bir VAR çerçevesi geliştirmişlerdir. Bu doğrultuda çalışmada, Diebold ve Yılmaz (2012), N değişkenli vektör otoregsesif modelle ilişkili olarak yönlü varyans ayrıştırmasına dayanan yönlü yayılım ölçüsü metodu kullanılmıştır.

$\mathrm{N}$ değişkenli, kovaryans durağan $\operatorname{VAR}(\mathrm{p})$ modeli eşitlik 2'de verilmiştir.

$$
x_{t}=\sum_{i=1}^{p} \phi_{i} x_{t-i}+\varepsilon_{t}
$$

Eşitlikte yer alan $\varepsilon_{t} \sim N\left(0, \sum_{\epsilon}\right)$ bağımsız ve türdeş dağılım gösteren bir vektör olup,

$\phi_{i}, i=1, \ldots, p$ için matrisin katsayılarını ifade etmektedir.

Eşitlik 2'de yer alan VAR modelinin hareketli ortalama gösterimi eşitlik 3'te verilmiştir:

$$
\begin{gathered}
x_{t}=\sum_{i=0}^{\infty} A_{i} \varepsilon_{t-i} \\
A_{i}=\phi_{1} A_{i-1}+\phi_{2} A_{i-2}+\ldots+\phi_{p} A_{i-p},
\end{gathered}
$$

$A_{0}, N \quad x \quad N \quad$ birim matris ve $i<0$ için $A_{i}=0$. Eşitlik 3'te yer alan $A_{i}$, özyineleme kuralına uygun olan katsayılar matrisini göstermektedir. 
Hareketli ortalama gösterimi, varyans ayrışmasının hesaplanmasını sağladığından dolayı sistemin dinamiklerini anlamada önemli bir rol oynamaktadır. Diebold ve Yılmaz (2012) hesaplanan varyans ayrıştırmasının, her bir değişkenin tahmin hatası varyanslarını çeşitli sistem şoklarına atfedilebilen parçalara ayrıştı̆̆ını belirtmiştir (Diebold ve Yılmaz, 2012, s. 58).

Varyans ayrıştırmaları, her bir değişkenin $\mathrm{H}$ adım ileri tahmin hatasını çeşitli piyasa şoklarına atfedilebilecek parçalara bölmemize izin verir. Bu ayrışmalarm bir araya getirilmesi daha sonra belirli bir piyasadan herhangi bir piyasaya ve tüm piyasalara yönelik yönlü bağlantılılığı hesaplamak için kullanilacaktır (Awartani, Aktham ve Cherif, 2016, s. 62).

Diebold ve Yılmaz (2012), VAR sisteminde değişken sıralamasının değişmediği varyans ayrışmalarını elde etmek için ilk kez Koop, Pesaran ve Potter (1996) ve Pesaran ve Shin (1998) (KPPS) genelleştirilmiş VAR çerçevesini kullanmaktadır.

KPPS tahmin hata varyans ayrışması ( $\mathrm{H}$ adım ileri) eşitlik 4'teki gibi hesaplanmaktadır;

$$
\theta_{\mathrm{ij}}^{\mathrm{g}}(H)=\frac{\sigma_{\mathrm{jj}}^{-1} \sum_{h=0}^{H-1}\left(e_{i}^{\prime} A_{h} \sum e_{j}\right)^{2}}{\sum_{h=0}^{H-1}\left(e_{i}^{\prime} A_{h} \sum A_{h}^{\prime} e_{i}\right)}
$$

Eşitlik 4 'te yer alan $\Sigma$, hata vektörü $(\varepsilon)$ için varyans matrisini ifade etmektedir. $\sigma_{j j}, j^{\prime} n c i$ hata teriminin standart sapmasını, $e_{i}, i^{\prime} n c i$ eleman için 1 veya 0 değerini alan seçim vektörünü ifade etmektedir.

Daha sonra varyans ayrışmasının her satırının birim toplamının elde edilmesinde, matrisin her bir girdisi satır toplamıyla eşitlik 5 'te gösterildiği üzere normalleştirilmektedir.

$$
\tilde{\theta}_{\mathrm{ij}}^{\mathrm{g}}(H)=\frac{\theta_{\mathrm{ij}}^{\mathrm{g}}(H)}{\sum_{j=1}^{N} \theta_{\mathrm{ij}}^{\mathrm{g}}(H)}
$$

Diebold ve Yılmaz (2012), KPPS tahmin hata varyans ayrışmasına dayanarak, tüm varlık sınıflarının volatilite şoklarının yayılımının toplam tahmin hata varyansına olan katkısını ölçmek için eşitlik 6' da yer alan toplam yayılım endeksini oluşturmuşlardır.

$$
S^{\mathrm{g}}(H)=\frac{\substack{\sum_{\mathrm{i}, \mathrm{j}=1}^{\mathrm{N}} i \neq j \\ i \neq j}}{N} \times 100
$$


Toplam volatilite yayılım endeksi, volatilite şoklarının tüm varlıklara nasıl yayıldığını gösterirken, genelleştirilmiş VAR modeli yaklaşımı, genelleştirilmiş varyans ayrışma matrisinin normalleştirilmiş elemanlarını kullanarak varlık sınıfları arasındaki volatilite yayılımlarının yönü hakkında da bilgi vermektedir (Diebold ve Yilmaz, 2012).

Dolayısıyla diğer tüm piyasalardan (j), (i) piyasasına yönelik yönlü yayılımlar eşitlik 7'deki gibi hesaplanmaktadır.

$$
S_{i .}^{g}(H) \leftarrow=\frac{\sum_{\substack{j=1 \\ j \neq i}}^{\mathbb{N}} \tilde{\theta}_{\mathrm{ij}}^{\mathrm{g}}(H)}{N} \times 100
$$

Benzer şekilde (i) piyasasından, diğer tüm piyasalara (j) yönelik yönlü yayılımlar da eşitlik 8'deki gibi hesaplanmaktadır.

$$
S_{i .}^{g}(H) \rightarrow=\frac{\sum_{\substack{j=1 \\ j \neq i}}^{\mathbb{N}} \tilde{\theta}_{\mathrm{ji}}^{\mathrm{g}}(H)}{N} \times 100
$$

Son olarak diğer tüm piyasalara aktarılan ve bunlardan alınan brüt volatilite şokları arasındaki fark olarak tanımlanan net yönlü volatilite yayılımı eşitlik 9'daki gösterildiği gibi hesaplanmaktadır.

$$
S_{i}^{g}(H)=S_{. i}^{g}(H) \rightarrow .-S_{i .}^{g}(H) \leftarrow .
$$

Çalışmada yayılma dinamiklerini yakalamak için 200 günlük kayan pencereler yaklaşımı kullanılmıştır. Ayrıca, tahmin hata varyans ayrışması için $(\mathrm{H}=10)$ ve VAR model için gecikme uzunluğu 4 olarak belirlenmiştir.

\section{Bulgular}

Çalışmada öncelikle borsa endekslerine ait logaritmik volatilitelerin tanımlayıcı istatistiklerine yer verilmiştir. Daha sonra volatilite bağlantılılık sonuçları açıklanmıştır. Borsa endekslerine ait logaritmik volatilite serilerinin tanımlayıcı istatistikleri ve bu volatilite serilerine ait grafikler aşağıda sırasıyla Tablo 1 ve Şekil 2'de sunulmuştur. 
Tablo 1. Borsa endekslerine ait logaritmik volatilite serilerinin tanımlayıcı istatistikleri

\begin{tabular}{llllllll}
\hline & Brezilya & Rusya & Hindistan & Çin & Endonezya & Meksika & Türkiye \\
\hline Ortalama & -8.78251 & -9.21165 & -9.54141 & -9.43966 & -9.752758 & -9.66899 & -8.6606 \\
Maksimum & -3.13989 & -3.68837 & -4.53944 & -5.49953 & -4.193755 & -4.13409 & -4.17121 \\
Minimum & -12.4849 & -15.9066 & -12.788 & -12.9853 & -13.24718 & -13.2347 & -12.6609 \\
Std. Sapma & 1.027988 & 1.344806 & 1.134423 & 1.145584 & 1.214369 & 1.135504 & 1.224439 \\
Çarpıklı & 0.442745 & -0.20037 & 0.325448 & 0.325586 & 0.435235 & 0.336867 & 0.318277 \\
Basıklk & 3.952392 & 4.461472 & 3.057604 & 2.986493 & 3.171206 & 3.270191 & 3.069966 \\
\hline
\end{tabular}

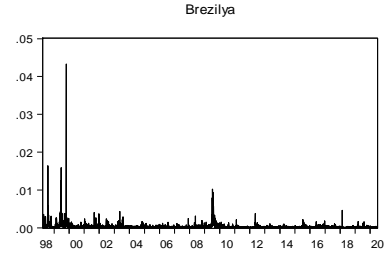

Çin

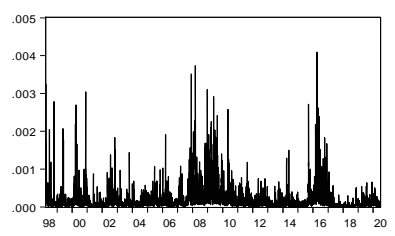

Türkiye

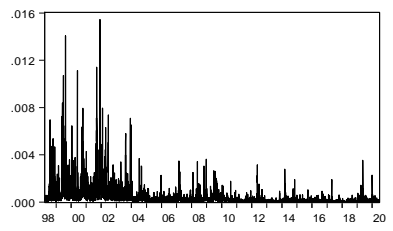

Rusya

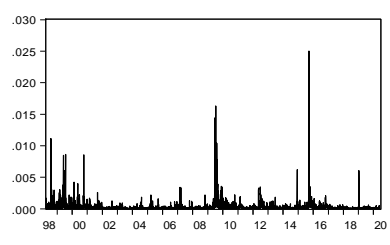

Endonezya

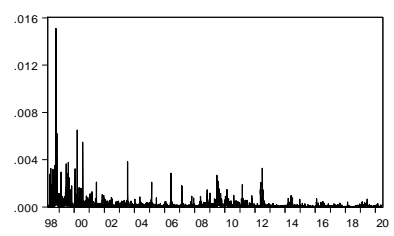

Hindistan

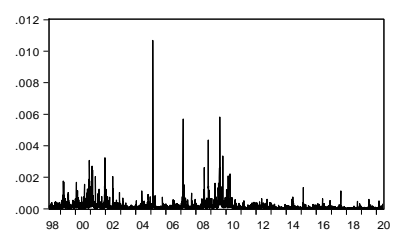

Meksika

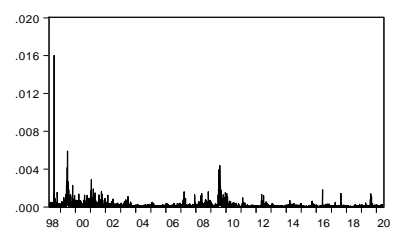

Şekil 2. Endekslerin günlük getirilerine ait volatilite serisi

Tablo 1 ve Şekil 2 birlikte incelendiğinde, Türkiye ve Brezilya borsa endeksinin oldukça oynak bir yapı sergilediği görülmektedir. Diğer ülkelere ait oynaklıklar ise görece olarak birbirine yakın seyretmektedir. Grafik 1 incelendiğinde, 1999 yılında Brezilya'da meydana gelen para krizinin yarattığı oynaklığın benzer tarihlerde Meksika borsa endeksinde de görüldüğü söylenebilir. Ayrıca, volatilite serilerinde 1997 Asya Krizi, 1999 Türkiye depremi ve Türkiye'de yaşanan 2000-2001 mali krizi kaynaklı oynaklıklar açık bir şekilde gözlemlenebilmektedir. 2007-2008 küresel finansal krizin yaratmış olduğu 
oynaklıklar ise tüm ülke piyasalarında grafiklerde görüldüğü üzere izlenebilmektedir. Gelişmekte olan ülkeler arasındaki volatilite bağlantılılık sonuçları Tablo 2'de verilmiştir.

Tablo 2. Volatilite Bağlantılılık Tablosu

\begin{tabular}{|c|c|c|c|c|c|c|c|c|}
\hline & Brezilya & Rusya & Hindistan & Çin & Endonezya & Meksika & Türkiye & $\begin{array}{l}\text { Diğerlerinden } \\
\text { yönlï }\end{array}$ \\
\hline Brezilya & 76.27 & 3.798 & 1.904 & 0.277 & 1.827 & 12.165 & 3.758 & 23.73 \\
\hline Rusya & 5.179 & 83.78 & 1.214 & 0.436 & 0.991 & 7.101 & 1.299 & 16.22 \\
\hline Hindistan & 3.757 & 1.968 & 80.634 & 1.125 & 3.718 & 4.489 & 4.31 & 19.366 \\
\hline Çin & 0.739 & 0.829 & 1.049 & 96.169 & 0.589 & 0.402 & 0.223 & 3.831 \\
\hline Endonezya & 5.128 & 1.619 & 4.074 & 0.624 & 77.769 & 5.715 & 5.072 & 22.231 \\
\hline Meksika & 12.221 & 4.35 & 3.095 & 0.496 & 2.68 & 73.258 & 3.9 & 26.742 \\
\hline Türkiye & 4.865 & 0.964 & 1.389 & 0.107 & 3.184 & 4.346 & 85.145 & 14.855 \\
\hline $\begin{array}{l}\text { Diğerlerine } \\
\text { doğru } \\
\text { yönlï }\end{array}$ & 31.889 & 13.528 & 12.725 & 3.065 & 12.988 & 34.218 & 18.561 & 126.974 \\
\hline $\begin{array}{l}\text { Kendisini } \\
\text { içeren } \\
\text { yönlï }\end{array}$ & 108.16 & 97.308 & 93.359 & 99.234 & 90.756 & 107.476 & 103.707 & $\begin{array}{l}\text { Toplam } \\
\text { Yayllma } \\
\text { Endeksi }\end{array}$ \\
\hline Net yaylma & 8.16 & -2.692 & -6.641 & -0.766 & -9.244 & 7.476 & 3.707 & $\begin{array}{l}(126.974 / 700)= \\
18.139 \%\end{array}$ \\
\hline
\end{tabular}

Tablo 2 incelendiğinde, diğer ülkelere doğru en yüksek finansal risk geçişi sırasıyla Meksika ve Brezilya borsalarından kaynaklanmaktayken, Asya ülkeleri arasından en yüksek finansal risk geçişi sırasıyla Türkiye, Rusya, Endonezya, Hindistan ve Çin borsalarından kaynaklanmaktadır. Diğer ülkelerden en fazla finansal risk alan ülkeler ise sırasıyla Meksika, Brezilya, Endonezya, Hindistan, Rusya, Türkiye ve Çin olarak gerçekleşmiştir. Dolayısıyla, Meksika ve Brezilya hem risk geçişi noktasında hem de risk alımı noktasında önde olan iki ülke olarak ortaya çımaktadır. Diğer yandan Meksika'nın yaymış olduğu risk en çok sırasıyla Brezilya'yı (12.165), Rusya'yı (7.101), Endonezya'yı (5.715), Hindistan'1 (4.489), Türkiye'yi (4.346) ve Çin'i (0.402) etkilerken, Brezilya'nın yaymış olduğu risk de en çok sırasıyla Meksika'yı (12.221), Rusya'yı (5.179), Endonezya'yı (5.128), Türkiye'yi (4.865), Hindistan'1 (3.757), ve Çin'i (0.739) etkilemiştir. Bu durum finansal bağlantılılık noktasında Meksika ve Brezilya'nın finansal sisteminin birbirlerine bağlı olduğunu ortaya koymaktadır. 
Piyasalara gelen yönlü ve piyasalardan giden yönlü yayılımlara ilişkin grafikler sırasıyla Şekil 3 ve Şekil 4'te sunulmuştur.
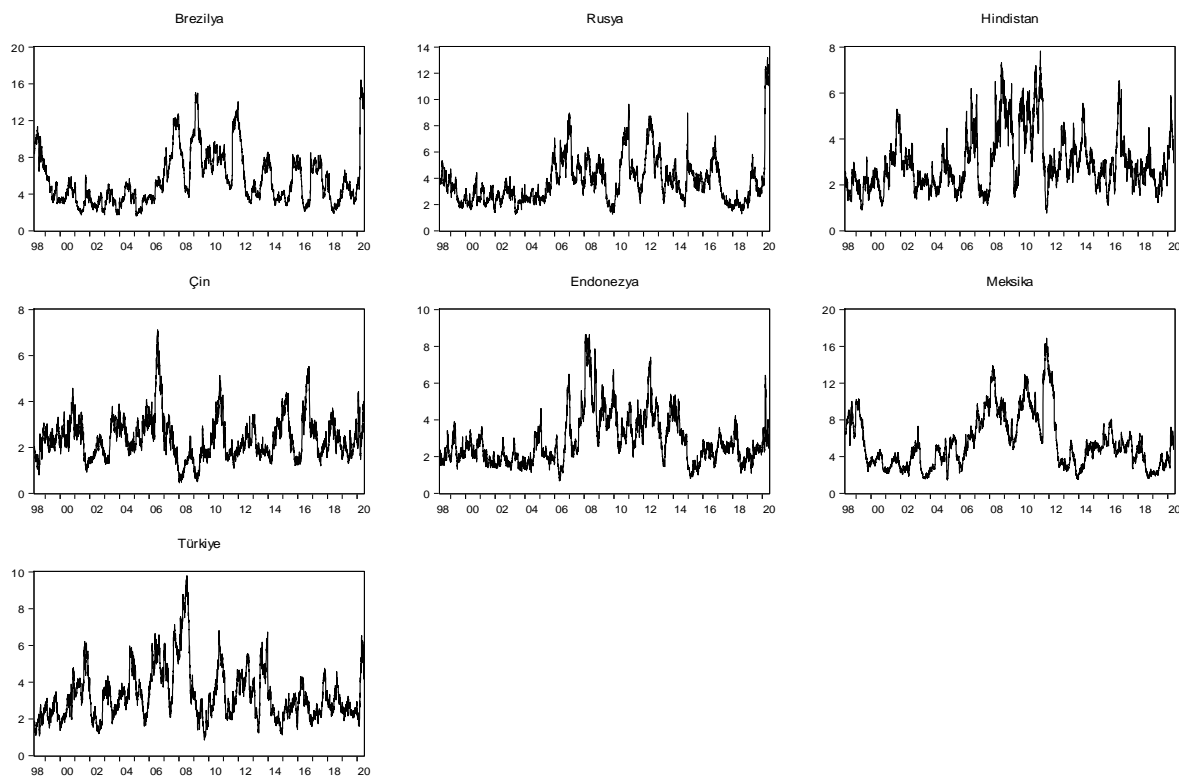

Şekil 3. Diğer piyasalardan gelen yönlü volatilite yayılımı
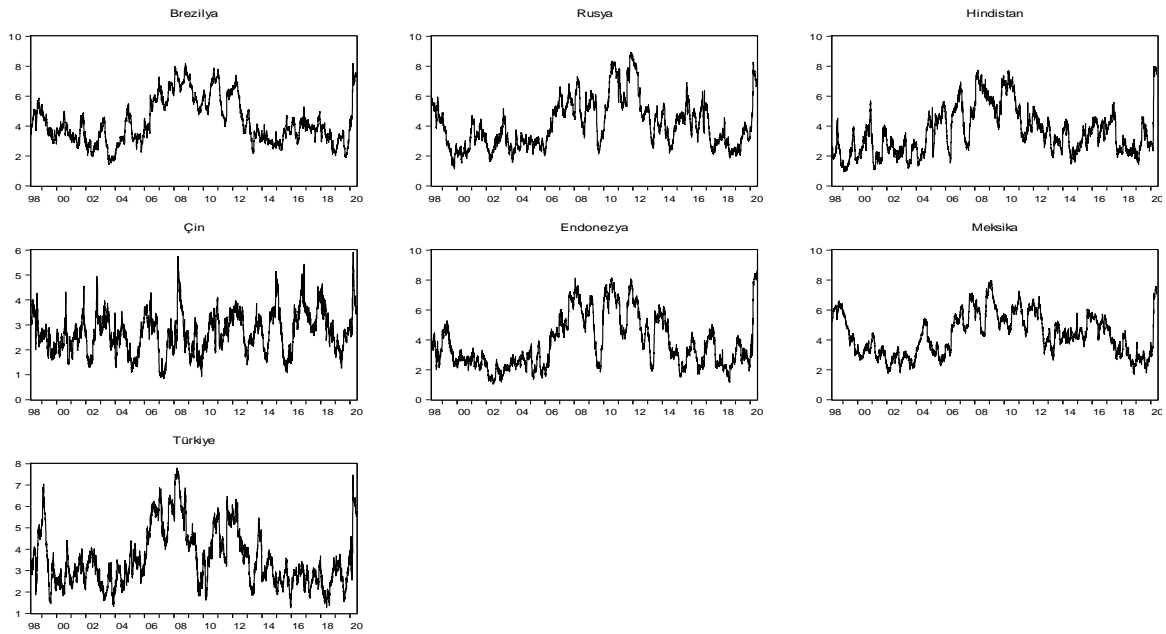

Şekil 4. Diğer piyasalara giden yönlü volatilite yayılımı 
Aşağıdaki yer alan Şekil 5 ise 200 günlük kayan pencereler yaklaşımı çerçevesine 10 günlük tahmin hatası varyans ayrışmaları üzerinden tahmin edilen toplam yayılma endeksini ve örneklem dönemi boyunca yerel bazda ülke piyasalarında ve küresel bazda uluslararası piyasalarda yaşanan olaylar karşısında endeksin verdiği tepkiyi göstermektedir.

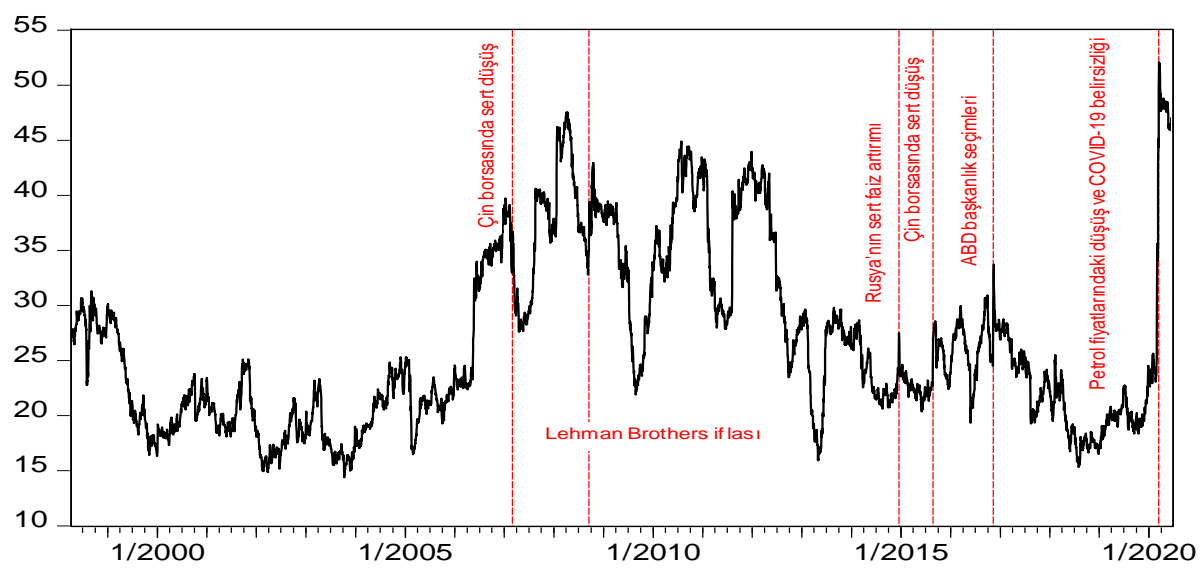

Şekil 5. 200 Günlük Kayan Pencereler Yaklaşımına Göre Elde Edilen Toplam Volatilite Yayılımı

Şekil 5'te yer alan toplam yayılım endeksinin yükseldiği dönemlerdeki finansal olaylar incelendiğinde; 27 Şubat 2007 tarihinde Şanghay Bileşik Endeksi yaklaşık \%8.49 değer kaybetmesi; 15 Eylül 2008'de Amerika Birleşik Devletleri'nin en büyük dördüncü yatırım bankası Lehman Brothers'ın iflasını açılaması; 16 Aralık 2014 tarihinde Ruble'de yaşanan serbest düşüşe karşı Rusya Merkez Bankası'nın 1998 Rusya ekonomik krizinden bu yana gerçekleştirdiği en büyük faiz artırımına gitmesi; 24 Ağustos 2015 tarihinde Şanghay Bileşik Endeksi'nin 2007 yılında yaşadığı düşüşe benzer olarak yaklaşık \%8.50 değer kaybetmesi; 9 Kasım 2016 ABD Başkanlık seçimi sonuçları; 11 Mart 2020 tarihinde Dünya Sağlık Örgütü tarafından COVID-19'un küresel salgın ilan edilmesi ve 20 Nisan 2020 tarihinde Mayıs ayı itibariyle vadesi dolacak olan Batı Teksas petrol fiyatlarında (WTI) yaşanan sert düşüşün oynaklığa neden olduğu görülmektedir.

Özellikle COVID-19 küresel salgının yarattığı endişenin piyasalarda yarattı̆̆ı oynaklık açıkça görülmektedir. Örneklem dönemi boyunca ortalama 
26.44 olan endeks küresel salgının yarattı̆̆ 1 etkiyle birlikte yaklaşık 52.09 seviyesine kadar gelmiştir.

\section{Sonuç}

Küreselleşme ve paralelinde yaşanan teknolojik gelişmeler dünya genelinde bilgi akış hızını oldukça etkilemiştir. Bir ülke ekonomisinde ya da piyasasında yaşanan bir gelişmenin farklı piyasalarda duyulma hızı önceleri aylarca veya günlerce süren bir süreç iken günümüzde dakikalarla ölçülmektedir. Dolayısıyla bu durum finansal piyasaların entegrasyonunu ve uluslararası piyasalara katılımı kolaylaştıran ve hızlandıran bir etmen olarak görülebilir. Finansal piyasaların entegrasyonu ve bilgi akışının hızlanması ile risklerini azaltmak isteyen portföy sahipleri uluslararası çeşitlendirme yoluyla birçok ülke piyasasında işlem yapmaktadır. Ayrıca artan profesyonel portföy yönetimi şirketleri de uluslararası çeşitlendirmeye destek sağlamaktadır. Yaşanan bu gelişmeler dikkate alındığında, bir ülke piyasasında yaşanan bir paniğin ya da yatırım fırsatının diğer ülke piyasalarını da kısa bir süre içerisinde etkilemesi beklenen bir sonuçtur.

Piyasaların entegrasyonu ve finansal liberalizasyon araştırmacıları piyasalar arasındaki etkileşimin incelenmesine yönlendirmiştir. Bu etkinin analizi ve kavranması piyasa düzenleyiciler ve katılımcıları için önem arz etmektedir. Bu sebeple, piyasalar arasındaki etkileşimi ölçmek amacıyla volatilite yayılımı konusu literatürde yer edinmeye başlamış ve konu ile ilgili araştırmalar günden güne artmaktadır. Bu doğrultuda bu çalışmada, gelişmekte olan ülke gruplarından E7 ülke piyasaları (Brezilya, Rusya, Hindistan, Çin, Endonezya, Meksika ve Türkiye) arasındaki finansal bağlantılılık 02 Temmuz 1997-24 Haziran 2020 dönemi için Diebold ve Yılmaz $(2009,2012)$ yöntemi ile incelenmiştir.

Çalışmada öncelikle E7 ülke borsalarına ait incelenen dönem için günlük logaritmik volatilite serileri elde edilmiştir. Daha sonra logaritmik volatilite serilerinden hareketle E7 piyasaları arasındaki bağlantılılığı ölçek amacıyla Diebold ve Yılmaz $(2009,2012)$ metodolojisini takiben volatilite bağlantılılık tablosu elde edilmiştir. Elde edilen bulgular incelendiğinde, E7 ülke piyasaları arasındaki toplam risk yayılımı, oldukça düşük çkmıştır. Özellikle diğer ülkelere doğru en yüksek finansal risk geçişinin ve risk alışının sırasıyla Mek- 
sika ve Brezilya borsalarından kaynaklandığı görülmüştür. Ancak bu iki ülkenin birbirlerine yaymış olduğu riskler, diğer ülkelere yaymış oldukları ve diğer ülkelerden almış oldukları risklerin büyük bir bölümünü oluşturmaktadır. Bu durumun temel nedeni, her iki ülkenin de aynı coğrafi bölgede yer alması ile açıklanabilir. Benzer durum Çin borsası dışındaki Asya borsaları için de görülmektedir. Bu noktada Rusya, Hindistan ve Türkiye borsasının diğer ülke piyasalarına yaymış olduğu ve diğer ülke piyasalarından almış oldukları risk geçişinin benzer olduğu görülmektedir. Ancak 200 günlük kayan pencereler yaklaşımı çerçevesinde E7 ülke borsalarının örneklem dönemi boyunca çeşitli finansal olaylara tepki verdiği gözlemlenmiştir. Bu olaylar içerisinde 2020 yılında dünyayı etkisi altına alan COVID-19 pandemisi finansal piyasalarda oynaklığın ve risk geçişinin en yüksek olduğu dönem olarak gözlemlenmiştir. E7 ülkelerindeki risk geçişleri dikkate alındığında Çin borsasının diğer altı ülke piyasasından ayrıldığı görülmüştür. Hem risk yayma hem de risk alma noktasında Çin en düşük seviyede kalmıştır. Çin ile Hindistan, aralarında benzer finansal risk geçişlerine sahip olduğu görülmüştür. Dolayısıyla, Çin menkul kıymetler piyasasına yatırım yapmak uluslararası yatırımcıların portföylerindeki riski yönetmelerine yardımcı olabilir.

Sonuç olarak, çalışmadan elde edilen bulgular dikkate alındığında çalışmanın portföy çeşitlendirmesinde ve piyasa volatilitesinin tahmin edilmesi için portföy yöneticileri ve piyasa düzenleyiciler için önem arz ettiği düşünülmektedir. Konu ile ilgili gelecekte farklı varlık piyasaları üzerinde yapılacak araştırmalar literatürün genişlemesine katkı sağlamakla birlikte yatırımcllara önemli bilgiler sunacaktır. 


\title{
EXTENDED ABSTRACT
}

\section{Financial Connectedness in Emerging Markets}

\author{
* \\ Eray Gemici \\ Gaziantep University
}

The volatility in the financial markets can be caused by shocks from local markets as well as from international financial events. However, in today's conditions, the local crises with the effect of financial liberalization do not only affect that market. Because international market participants can instantly learn about the shock experienced in a country like citizens of that country and take positions in the markets accordingly. Therefore, in today's world where information spreads rapidly, positive or negative events experienced in financial markets can spread to various country markets. For this reason, the issue of inter-market connectedness and volatility spillover has become very important for both states and regulators trying to keep their financial markets under control, as well as portfolio managers and investors, and it is still being studied in different asset markets by researchers in financial literature with various methods.

Globalization and technological developments in parallel have affected the rate of information flow worldwide. While the speed of hearing development in a country's economy or market in different markets was a process that previously took months or days, today it is measured in minutes. Therefore, this situation can be seen as a factor that facilitates and accelerates the integration of financial markets and participation in international markets. Portfolio owners who want to reduce their risks by the integration of financial markets and the acceleration of information flow operate in many countries' markets through international diversification. In addition, increasing professional portfolio management companies support international diversification. Considering these developments, it is an expected result that a panic or investment opportunity in a country's market will affect the markets of other countries in a short time. Therefore, the integration of markets and financial liberalization has led researchers to examine the interaction between markets. Analysis and understanding of 
this effect are important for market regulators and participants. For this reason, the subject of volatility spillover has started to take place in the literature in order to measure the interaction between markets and the researches on the subject is increasing day by day.

The aim of this study is to examine the financial connectedness between the emerging E7 markets (Brazil, Russia, India, China, Indonesia, Mexico, and Turkey) using the Diebold and Yilmaz $(2009,2012)$ method. There are a limited number of studies in the literature that follows the Diebold and Yilmaz $(2009,2012)$ methodology. It is thought that the study will contribute to the existing literature, because to the best of our knowledge, it deals with a different country group than the studies in the literature. In the study, the volatility of the daily returns of the stock exchanges of seven developing countries for the period of 02 July 1997 - 24 June 2020 was determined as a data set. The data consists of a total of 5,996 days of observations.

One of the econometric methods frequently used in the literature is the method suggested by Diebold and Yilmaz $(2009 ; 2012)$ and used in estimating the directional measure of volatility spillover. Diebold and Yilmaz (2009) stated that the method can be used to measure return or return volatility, assets within and between countries, asset portfolios, and spreading trends, cycles, and explosions between asset markets.

Findings from the study reveal that the Mexican and Brazilian stock markets are the countries with the highest financial risk transition to other countries. The highest financial risk transition to other countries stem from respectively Turkey, Russia, Indonesia, India, and China among Asian stock markets. Therefore, Mexico and Brazil emerge as the two leading countries in both risk transition and risk-taking. This situation reveals that the financial systems of Mexico and Brazil are interdependent in terms of financial connectedness. On the other hand, during the sampling period, the response of the total spillover index against the events experienced in local markets and international markets on a global basis during the sampling period was examined within the framework of the 200-day rolling windows approach. The sharp decline in the Shanghai Composite Index, the bankruptcy of Lehman Brothers, the sharp interest rate hike by the Russian Central Bank, the US Presidential election results, the global epidemic of COVID-19 and the sharp fall in West Texas oil prices led to 
the rise in the total spillover index. In particular, the volatility in the markets caused by the concern caused by the COVID-19 global epidemic has been very effective.

As a result, considering the findings of the study, it is thought that the study is important for portfolio managers and market regulators in portfolio diversification and for estimating market volatility. Future research on the subject will help investors and the expansion of the literature by addressing different asset markets.

\section{Kaynakça / References}

Abbas, G., Hammoudeh, S., Shahzad, S. J. H., Wang, S. ve Wei, Y. (2019). Return and volatility connectedness between stock markets and macroeconomic factors in the G-7 countries. Journal of Systems Science and Systems Engineering, 28(1), 1-36. doi:10.1007/s11518-018-5371-y

Alom, F., Ward, B. ve Hu, B. (2011). Cross country mean and volatility spillover effects of food prices: Multivariate GARCH analysis. Economics Bulletin, 31(2), 1439-1450.

Alotaibi, A. R. ve Mishra, A. V. (2015). Global and regional volatility spillovers to GCC stock markets. Economic Modelling, 45, 38-49. doi:10.1016/j.econ$\bmod .2014 .10 .052$

Aloui, C. (2011). Latin American stock markets' volatility spillovers during the financial crises: A multivariate FIAPARCH-DCC framework. doi:10.1080/17520843.2011.590597

Awartani, B., Aktham, M. ve Cherif, G. (2016). The connectedness between crude oil and financial markets: Evidence from implied volatility indices. Journal of Commodity Markets, 4(1), 56-69. doi:10.1016/j.jcomm.2016.11.002

Baele, L. (2005). Volatility spillover effects in European equity markets. The Journal of Financial and Quantitative Analysis, 40(2), 373-401.

Bala, D. A. ve Takimoto, T. (2017). Stock markets volatility spillovers during financial crises: A DCC-MGARCH with skewed-t density approach. Borsa Istanbul Review, 17(1), 25-48. doi:10.1016/j.bir.2017.02.002

Balcılar, M., Özdemir, Z. A. ve Özdemir, H. (2019). Dynamic return and volatility spillovers among S\&P 500, crude oil, and gold. International Journal of Finance \& Economics, n/a(n/a). doi:10.1002/ijfe.1782

Baruník, J., Kočenda, E. ve Vácha, L. (2016). Asymmetric connectedness on the U.S. stock market: Bad and good volatility spillovers. Journal of Financial Markets, 27, 55-78. doi:10.1016/j.finmar.2015.09.003 
Beirne, J., Caporale, G. M., Schulze-Ghattas, M. ve Spagnolo, N. (2013). Volatility spillovers and contagion from mature to emerging stock markets. Review of International Economics, 21(5), 1060-1075. doi:10.1111/roie.12091

Ben Rejeb, A. (2016, Temmuz). Volatility Spillover between Islamic and conventional stock markets: Evidence from quantile regression analysis. MPRA Paper. 10 Ağustos 2020 tarihinde https://mpra.ub.uni-muenchen.de/73302/ adresinden erişildi.

Çamlıca, F., Güneş, D. ve Özen, E. (2017). A financial connectedness analysis for Turkey.

Cardona, L., Gutiérrez, M. ve Agudelo, D. A. (2017). Volatility transmission between US and Latin American stock markets: Testing the decoupling hypothesis. Research in International Business and Finance, 39, 115-127. doi:10.1016/j.ribaf.2016.07.008

Chancharoenchai, K. ve Dibooglu, S. (2006). Volatility spillovers and contagion during the Asian crisis: Evidence from six Southeast Asian stock markets. Emerging Markets Finance and Trade, 42(2), 4-17.

Chow, H. K. (2017). Volatility Spillovers and Linkages in Asian Stock Markets. Emerging Markets Finance and Trade, 53(12), 2770-2781. doi:10.1080/1540496X.2017.1314960

Christiansen, C. (2007). Volatility-spillover effects in European bond markets. European Financial Management, 13(5), 923-948. doi:10.1111/j.1468036X.2007.00403.x

Diebold, F. X. ve Y1lmaz, K. (2009). Measuring financial asset return and volatility spillovers, with application to global equity markets. The Economic Journal, 119(534), 158-171. doi:10.1111/j.1468-0297.2008.02208.x

Diebold, F. X. ve Y1lmaz, K. (2012). Better to give than to receive: Predictive directional measurement of volatility spillovers. International Journal of Forecasting, Special Section 1: The Predictability of Financial Markets, 28(1), 5766. doi:10.1016/j.ijforecast.2011.02.006

Do, A., Powell, R., Yong, J. ve Singh, A. (2019). Time-varying asymmetric volatility spillover between global markets and China's A, B and H-shares using EGARCH and DCC-EGARCH models. The North American Journal of Economics and Finance, 101096. doi:10.1016/j.najef.2019.101096

Du, X., Yu, C. L. ve Hayes, D. J. (2011). Speculation and volatility spillover in the crude oil and agricultural commodity markets: A Bayesian analysis. Energy Economics, 33(3), 497-503. doi:10.1016/j.eneco.2010.12.015 
Faizulayev, A. ve Wada, I. (2019). Spillover Effect of Interest Rate Volatility on Banking Sector Development in Nigeria: Dynamic ARDL Bound Test Approach. N. Ozatac ve K. K. Gokmenoglu (Ed.), Global Issues in Banking and Finance içinde (s. 111-125). Springer Proceedings in Business and Economics Cham: Springer International Publishing. doi:10.1007/978-3-03030387-7_8

Gamba-Santamaria, S., Gomez-Gonzalez, J. E., Hurtado-Guarin, J. L. ve Melo-Velandia, L. F. (2017). Stock market volatility spillovers: Evidence for Latin America. Finance Research Letters, 20, 207-216. doi:10.1016/j.frl.2016.10.001

Gong, X.-L., Liu, X.-H., Xiong, X. ve Zhang, W. (2019). Financial systemic risk measurement based on causal network connectedness analysis. International Review of Economics \& Finance, 64, 290-307. doi:10.1016/j.iref.2019.07.004

Jeong, D. ve Park, S. (2018). The more connected, the better? Impact of connectedness on volatility and price discovery in the Korean financial sector. Managerial Finance, 44(1), 46-73. doi:10.1108/MF-09-2016-0277

Joshi, P. (2011). Return and volatility spillovers among Asian stock markets. SAGE Open, 1(1), 2158244011413474. doi:10.1177/2158244011413474

Kamışl, M., Kamışli, S. ve Temizel, F. (2019). Empirical evidence of the relationships between bitcoin and stock exchanges: Case of return and volatility spillover. U. Hacioglu (Ed.), Blockchain Economics and Financial Market Innovation: Financial Innovations in the Digital Age içinde (s. 293-318). , Contributions to Economics Cham: Springer International Publishing. doi:10.1007/978-3-030-25275-5_15

Karali, B. ve Ramirez, O. A. (2014). Macro determinants of volatility and volatility spillover in energy markets. Energy Economics, 46, 413-421. doi:10.1016/j.eneco.2014.06.004

Kırkulak Uludag, B. ve Khurshid, M. (2019). Volatility spillover from the Chinese stock market to E7 and G7 stock markets. Journal of Economic Studies, 46(1), 90-105. doi:10.1108/JES-01-2017-0014

Koop, G., Pesaran, M. H. ve Potter, S. M. (1996). Impulse response analysis in nonlinear multivariate models. Journal of Econometrics, 74(1), 119-147. doi:10.1016/0304-4076(95)01753-4

Korkmaz, T., Çevik, E. İ. ve Atukeren, E. (2012). Return and volatility spillovers among CIVETS stock markets. Emerging Markets Review, 13(2), 230-252. doi:10.1016/j.ememar.2012.03.003

Kumar, A. S. ve Kamaiah, B. (2017). Returns and volatility spillover between Asian equity markets: A wavelet approach. Economic Annals, 62(212), 63-83. 
Lee, J. (2009). Currency risk and volatility spillover in emerging foreign exchange markets (SSRN Scholarly Paper No: ID 1650049). Rochester, NY: Social Science Research Network. doi:10.2139/ssrn.1650049

Li, Y. ve Giles, D. E. (2015). Modelling volatility spillover effects between developed stock markets and Asian Emerging stock markets. International Journal of Finance \& Economics, 20(2), 155-177. doi:10.1002/ijfe.1506

Liow, K. H. ve Huang, Y. (2018). The dynamics of volatility connectedness in international real estate investment trusts. Journal of International Financial Markets, Institutions and Money, 55, 195-210. doi:10.1016/j.intfin.2018.02.003

Mensi, W., Boubaker, F. Z., Al-Yahyaee, K. H. ve Kang, S. H. (2018). Dynamic volatility spillovers and connectedness between global, regional, and GIPSI stock markets. Finance Research Letters, 25, 230-238. doi:10.1016/j.frl.2017.10.032

Mishra, A. (2019). Crude oil, stock market, and foreign exchange return volatility and spillover: A GARCH DCC analysis of Indian and Japanese financial market. International Journal of Business Innovation and Research, 20(1), 2546. doi:10.1504/IJBIR.2019.101687

Nazlıoglu, S., Erdem, C. ve Soytaş, U. (2013). Volatility spillover between oil and agricultural commodity markets. Energy Economics, 36, 658-665. doi:10.1016/j.eneco.2012.11.009

$\mathrm{Ng}$, A. (2000). Volatility spillover effects from Japan and the US to the PacificBasin. Journal of International Money and Finance, 19(2), 207-233. doi:10.1016/S0261-5606(00)00006-1

Parkinson, M. (1980). The Extreme Value Method for Estimating the Variance of the Rate of Return. The Journal of Business, 53(1), 61-65.

Pesaran, H. H. ve Shin, Y. (1998). Generalized impulse response analysis in linear multivariate models. Economics Letters, 58(1), 17-29. doi:10.1016/S01651765(97)00214-0

Polat, O. (2018). Hisse senedi piyasalarında finansal bağlantılılık analizi. Politik Ekonomik Kuram, 2(1), 73-86.

Priya, S. (2008). Volatility spillover in bullion and energy futures and spot markets. Journal of Emerging Financial Markets, 1(1), 85-107.

Qarni, M. O., Gulzar, S., Fatima, S. T., Khan, M. J. ve Shafi, K. (2019). Inter-markets volatility spillover in U.S. bitcoin and financial markets. Journal of Business Economics and Management, 20(4), 694-714. doi:10.3846/jbem.2019.8316 
Qayyum, A. ve Kemal, A. R. (2006). Volatility spillover between the stock market and the foreign exchange market in Pakistan (SSRN Scholarly Paper No: ID 963308). Rochester, NY: Social Science Research Network. doi:10.2139/ssrn.963308

Reboredo, J. C. ve Ugolini, A. (2020). Price connectedness between green bond and financial markets. Economic Modelling, 88, 25-38. doi:10.1016/j.econmod.2019.09.004

Singh, P., Kumar, B. ve Pandey, A. (2010). Price and volatility spillovers across North American, European and Asian stock markets. International Review of Financial Analysis, 19(1), 55-64. doi:10.1016/j.irfa.2009.11.001

Toraman, C., İğde, M., Buğan, M. F. ve Kılıç, Y. (2016). Volatility spillover effect from conventional stock markets to Islamic stock markets. International Journal of Academic Research in Economics and Management Sciences, 5(4), 2226-3624.

Umer, U. M., Coskun, M. ve Kiraci, K. (2018). Time-varying return and volatility spillover among eagles stock markets: A multivariate garch analysis. Journal of Finance and Economics Research, 3(1), 23-42.

Vo, X. V. ve Tran, T. T. A. (2020). Modelling volatility spillovers from the US equity market to ASEAN stock markets. Pacific-Basin Finance Journal, 59, 101246. doi:10.1016/j.pacfin.2019.101246

Wu, F., Guan, Z. ve Myers, R. J. (2011). Volatility spillover effects and cross hedging in corn and crude oil futures. Journal of Futures Markets, 31(11), 10521075. doi:10.1002/fut.20499

Wu, M. ve Zhu, Z. (2019). The volatility spillover effect between the international crude oil futures price and China's stock market-multivariate bekk-garch model based on wavelet multiresolution. International Journal of Financial Research, 10(4).

Yarovaya, L., Brzeszczyński, J. ve Lau, C. K. M. (2016). Intra- and inter-regional return and volatility spillovers across emerging and developed markets: Evidence from stock indices and stock index futures. International Review of Financial Analysis, 43, 96-114. doi:10.1016/j.irfa.2015.09.004

Yllmaz, K. (2010). Return and volatility spillovers among the East Asian equity markets. Journal of Asian Economics, The Financial Crisis of 2008-09: Origins, Issues, and Prospects, 21(3), 304-313. doi:10.1016/j.asieco.2009.09.001 
Yoon, S.-M., Al Mamun, M., Uddin, G. S. ve Kang, S. H. (2019). Network connectedness and net spillover between financial and commodity markets. The North American Journal of Economics and Finance, 48, 801-818. doi:10.1016/j.najef.2018.08.012

Zeng, T., Yang, M. ve Shen, Y. (2020). Fancy Bitcoin and conventional financial assets: Measuring market integration based on connectedness networks. Economic Modelling, 90, 209-220. doi:10.1016/j.econmod.2020.05.003

Zhou, X., Zhang, W. ve Zhang, J. (2012). Volatility spillovers between the Chinese and world equity markets. Pacific-Basin Finance Journal, 20(2), 247-270. doi:10.1016/j.pacfin.2011.08.002

\section{Kaynakça Bilgisi / Citation Information}

Gemici, E. (2020). Gelişmekte olan piyasalarda finansal bağlantılılık. OPUS-Uluslararası Toplum Araştırmaları Dergisi, 16(30), 3134-3160. DOI: 10.26466/opus.778653 